\title{
Effects of Amino Acids on the Crystallization of Calcium Tartrate Tetrahydrate
}

\author{
Sevgi Polat, Elif Aytan-Goze and Perviz Sayan \\ Department of Chemical Engineering, Faculty of Engineering, Marmara University, 34722, İstanbul, Turkey. \\ *Corresponding author: E-mail: perviz.sayan@marmara.edu.tr, \\ Phone: +90-2167773703, Fax: +90-2167773501
}

Received: 01-05-2020

\begin{abstract}
This work assesses the effects of various amino acids, including serine, alanine, methionine, and proline, on calcium tartrate tetrahydrate (CTT) crystals. The crystallization experiments were performed in batch mode at $25^{\circ} \mathrm{C}, \mathrm{pH} 9$ with three amino acid concentrations. The CTT crystals were characterized by XRD, FTIR, SEM, particle size and zeta potential analysis. All of the amino acids used in this study were found to significantly affect the surface electrical charge, size, and morphology of the obtained crystals. In addition, the thermal decomposition of the produced crystals obtained in pure media was examined and the obtained data were used to investigate the decomposition kinetics of the crystals with the help of three different model-free kinetic methods, namely Flynn-Wall-Ozawa (FWO), Kissinger-Akahira-Sunose (KAS), and Starink. The average activation energy of the crystals for the first, second, third, and fourth stages using the FWO, KAS, and Starink methods was calculated to be 91.0, 158.0, 249.1, and $224.8 \mathrm{~kJ} / \mathrm{mol} ; 89.6,155.9,250.7$, and 221.1 $\mathrm{kJ} / \mathrm{mol} ; 88.6,156.8,250.5$, and $220.4 \mathrm{~kJ} / \mathrm{mol}$, respectively. Thus, the results of this work are useful for selecting CTT morphology modifiers and explaining the decomposition kinetics of CTT crystals.
\end{abstract}

Keywords: Calcium tartrate; crystallization; amino acid; kinetics, model-free

\section{Introduction}

The physical properties of tartrate crystals hold significant research interest. Ferroelectric and piezoelectric tartrate crystals have been reported, and tartrate crystals are often used for controlling laser emissions. ${ }^{1,2}$ Among tartrate crystals, calcium tartrate has drawn the attention of many researchers because of its various applications in science and technology as well as in the field of pharmaceutical science, in addition to industrial uses. ${ }^{3}$ Besides these practical applications, calcium tartrate tetrahydrate (CTT) crystals are also reported as novel kidney stones in animals. ${ }^{4}$

CTT crystals are orthorhombic with a tetra molecular unit cell of dimensions $a=9.24, b=10.63$, and $c=9.66$ $\AA$ with space group $\mathrm{P} 2{ }_{1} 2_{1} 2_{1}$. There are two asymmetric carbons in calcium tartrate, so it forms three isomers: two chiral and one non-chiral (meso-form). The chiral levorotatory (-) isomer is the most common form in nature. CTT crystals have been shown to have ferroelectric and non-linear optical properties. ${ }^{5}$

In recent years, researchers in the field of solid-state science have shown significant interest in the growth and characterization of CTT crystals, either pure crystallization media or with added dopants, such as barium, strontium, cobalt, nickel, manganese, zinc, and cadmium. ${ }^{6-9}$ To date, most studies on pure CTT crystals have aimed at understanding the basic principles and the nature of the crystal growth phenomenon. ${ }^{2}$ In the present study, we investigated the crystallization of CTT in the presence of the amino acid additives serine, alanine, methionine, and proline. These additives were selected because so far only limited studies have been reported on CTT crystallization in the presence of various amino acids; our work should clarify their roles as crystallization-modifying additives. Thus, in this work, we assessed the crystalline structure, morphology, and particle size of crystals prepared using solutions with and without an amino acid additive. In addition, we hope to address the lack of literature on the thermal decomposition kinetics of CTT crystals using the model-free kinetic models of Flynn-Wall-Ozawa (FWO), Kissinger-Akahira-Sunose (KAS), and Starink models. Therefore, the thermal decomposition behavior of the prepared crystals was investigated in detail and used to explain the kinetic characteristics and calculate the activation energies for the decomposition of CTT crystals. 


\section{Experimental}

\section{1. Materials}

Calcium chloride dihydrate $\left(\mathrm{CCD}, \mathrm{CaCl}_{2} 2 \mathrm{H}_{2} \mathrm{O}\right)$ and tartaric acid $\left(\mathrm{TA}, \mathrm{C}_{4} \mathrm{H}_{6} \mathrm{O}_{6}\right)$ of analytical reagent grade were supplied by Merck, Darmstadt, Germany and used for the precipitation of CTT crystals. The amino acid additives alanine $\left(\mathrm{C}_{3} \mathrm{H}_{7} \mathrm{NO}_{2}\right)$, methionine $\left(\mathrm{C}_{5} \mathrm{H}_{11} \mathrm{NO}_{2} \mathrm{~S}\right)$, serine $\left(\mathrm{C}_{3} \mathrm{H}_{7} \mathrm{NO}_{3}\right)$, and proline $\left(\mathrm{C}_{5} \mathrm{H}_{9} \mathrm{NO}_{2}\right)$ of analytical reagent grade were also provided by Merck. Distilled water was used for the experiments.

\section{2. Preparation of Calcium Tartrate Tetrahydrate Crystals}

The CTT crystallization was carried out in batch mode at $25^{\circ} \mathrm{C}$ in a double-jacketed crystallizer with an active volume of $500 \mathrm{ml}$. CCD and TA were used as the reactants for CTT precipitation. The experimental setup is illustrated in Figure 1. suspension in the crystallizer was stirred at a rate of 300 $\mathrm{rpm}$. During the crystallization process, the $\mathrm{pH}$ of the solution was continuously monitored and maintained at $\mathrm{pH} 9$ by adding $\mathrm{NaOH}$ solution using an automatic $\mathrm{pH}$ control system.

The influence of different types and concentrations of amino acid on the crystallization of CTT was investigated in this study. At the beginning of the experiments, alanine, methionine, serine, and proline were added to the TA solution to provide the desired concentrations of 50,100 , and $200 \mathrm{ppm}$ in the crystallizer. After all of the reactants had been added to the crystallizer, the suspension was left to stir for half an hour. At the end of this time, the crystallizer contents were filtered and washed thoroughly with distilled water. The washing repeated was continued until no chloride ions remained. The presence of chloride ions was checked using $0.1 \mathrm{M}$ silver nitrate solution. The washed CTT crystals were then dried at room temperature and subjected to various characterization processes.

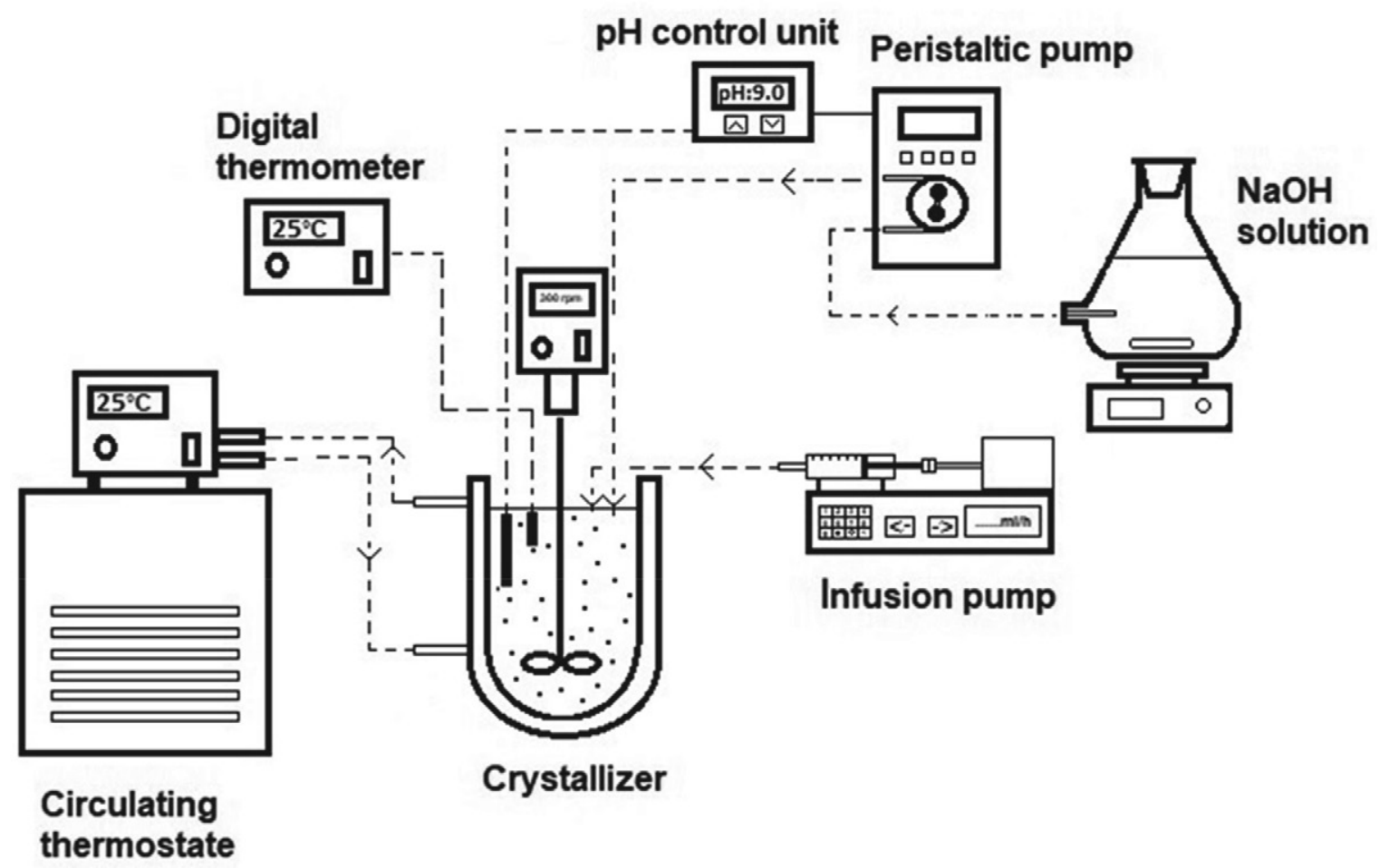

Figure 1. Experimental setup.

Firstly, $0.25 \mathrm{M}$ CCD and $0.25 \mathrm{M}$ TA solutions were prepared. To start the crystallization, $200 \mathrm{ml}$ of TA solution was placed into the crystallizer, followed by the addition of $0.1 \mathrm{M} \mathrm{NaOH}$ solution to adjust the $\mathrm{pH}$ to 9. The solution was maintained at a constant temperature of $25 \pm$ $0.5^{\circ} \mathrm{C}$ using a thermostat. After thermal equilibrium was reached, $200 \mathrm{ml}$ of CCD solution was fed into the crystallizer via an infusion pump at a flow rate of $1 \mathrm{ml} / \mathrm{min}$. The

\section{3. Characterization of the Calcium Tetrahydrate Crystals}

The structures of the prepared crystal samples were determined using a Bruker D2 Phaser benchtop $\mathrm{X}$-ray diffractometer $(30 \mathrm{kV}, 10 \mathrm{~mA})$ with $\mathrm{CuKa}$ radiation $(\lambda=1.5418 \AA)$ in the $2 \theta$ range of $10-60^{\circ}$. Fourier transform infrared spectrometry (FTIR; Shimadzu) was used to determine the functional groups of the crystals and to clarify their structures. The spectra were record- 
ed at room temperature in the wavenumber range of $600-4000 \mathrm{~cm}^{-1}$. The morphology of the CTT crystals was observed using a scanning electronic microscope (SEM, Zeiss EVO LS 10). The length and width of the samples were determined using Data Translation Image-Pro Plus image analysis software; at least 50 particles were counted to calculate the average aspect ratio of CTT. Zeta potential analysis was performed using a Malvern Zetasizer Nano ZS instrument to determine the surface charge of the CTT crystals obtained in pure and additive media. Measurements were repeated at least 10 times and the mean value was taken. The thermal behavior of the CTT crystals obtained in pure and amino acid-supplemented media was determined using a Setaram LABSYS Evo thermogravimetric analyzer in a nitrogen atmosphere between $30{ }^{\circ} \mathrm{C}$ and $850{ }^{\circ} \mathrm{C}$ with a heating rate of $5,10,20^{\circ} \mathrm{C} / \mathrm{min}$. Using the obtained data, the thermal decomposition kinetics for the CTT crystals obtained in pure media were investigated and activation energy was calculated.

\section{4. Kinetic Model Equations}

Thermogravimetric analysis is a common method used to investigate the thermal decomposition behavior of solids and to determine activation energy:

The decomposition rate of a solid can be defined as:

$$
\frac{d x}{d t}=k(T) f(x)
$$

where $f(x), k(T)$, and $t$ represent the reaction model, the reaction rate constant, and time, respectively. The rate constant, $k(T)$, can be defined by the Arrhenius equation, as shown in Eq. (2).

$$
k(T)=A \exp \left(-\frac{E}{R T}\right)
$$

where $A$ is the pre-exponential or frequency factor $\left(\mathrm{min}^{-1}\right)$, $E$ is the activation energy $(\mathrm{kJ} / \mathrm{mol}), T$ is the absolute temperature $(\mathrm{K})$, and $R$ is the ideal gas constant $(8.314 \mathrm{~J} / \mathrm{mol}$ $\mathrm{K})$.

The conversion $x$ is shown in Eq. (3):

$$
x=\frac{W_{0}-W_{t}}{W_{0}-W_{f}}
$$

where $W_{0}$ and $W_{f}$ are the initial and final sample mass, respectively, and $W_{t}$ is the sample weight at time $t$. For a constant heating rate, $\beta(\mathrm{K} / \mathrm{min})$ can be defined as:

$$
\beta=\frac{d T}{d t}
$$

For non-isothermal analysis, by substituting Eq. (4) into Eq. (1), the equation is given by Eq. (5).

$$
\frac{d x}{d T}=k(T) f(x)=\frac{A}{\beta} \exp \left(-\frac{E}{R T}\right) f(x)
$$

Integrating Eq. (5) gives Eq. (6):

$$
\int_{0}^{x} \frac{d x}{f(x)}=g(x)=\frac{A}{\beta} \int_{T_{0}}^{T} \exp \left(-\frac{E}{R T}\right) d T=\frac{A E}{\beta R} p(u)
$$

where $p(u)$ and $g(x)$ show the temperature integral and the integrated reaction model, respectively. The solution of this equation can be obtained by some approximations depending on the applied kinetic method. In this study, three common isoconversional kinetic methods, namely the Flynn-Wall-Ozawa (FWO), ${ }^{10,11}$ Kissinger-AkahiraSunose (KAS), ${ }^{12}$ and Starink ${ }^{13}$ methods, were used to determine the activation energies of the CTT crystals. Their linear equations are presented in Eqs. (7)-(9), respectively.

$$
\begin{aligned}
& \text { FWO: } \ln (\beta)=\ln \left(\frac{A E}{R g(x)}\right)-5.331-1.052 \frac{E}{R} \frac{1}{T} \\
& \text { KAS: } \ln \left(\frac{\beta}{T^{2}}\right)=\ln \left(\frac{A R}{E g(x)}\right)-\frac{E}{R T} \\
& \text { Starink: } \ln \left(\frac{\beta}{T^{1.92}}\right)=C-1.008 \frac{E}{R T}
\end{aligned}
$$

For any given value, it is possible to estimate $\mathrm{E}$ based on the gradients of the lines obtained from the plot of $\ln (\beta)$ versus $1 / T, \ln \left(\beta / T^{2}\right)$ versus $1 / T, \ln \left(\beta / T^{1.92}\right)$ versus $1 / T$ for the FWO, KAS, and Starink, models, respectively.

\section{Results and Discussion}

\section{1. XRD Analysis}

The XRD patterns of the CTT crystals obtained with and without different amino acids are presented in Figure 2. The experimentally observed XRD patterns for the crystals closely matched the patterns simulated using Rietveld refinement. The XRD results showed that the crystals obtained in pure media were in the form of CTT. Consistent with the literature ${ }^{14}$ the main peaks detected at 13.274 , $15.700,16.740,18.397,29.0250,29.418,33.269,40.165$, and $48.721^{\circ}$ corresponded to the (101), (111), (020), (200), (310), (301), (132), (104), and (342) planes of the orthorhombic structure, respectively, with space group P212121.

Unit cell dimensions of $a=9.637 \AA, b=10.583 \AA, c=$ $9.216 \AA, \alpha=\beta=\gamma=90^{\circ}$ were calculated for the CTT crystals using Materials Analysis Using Diffraction (MAUD) software, which was in agreement with the results of a previous study. ${ }^{15}$

Similar to the crystals prepared in pure media, all of the XRD peaks, regardless of the amino acids used, were attributed to CTT crystals and no other phase formations were observed. In other words, the addition of amino acids 

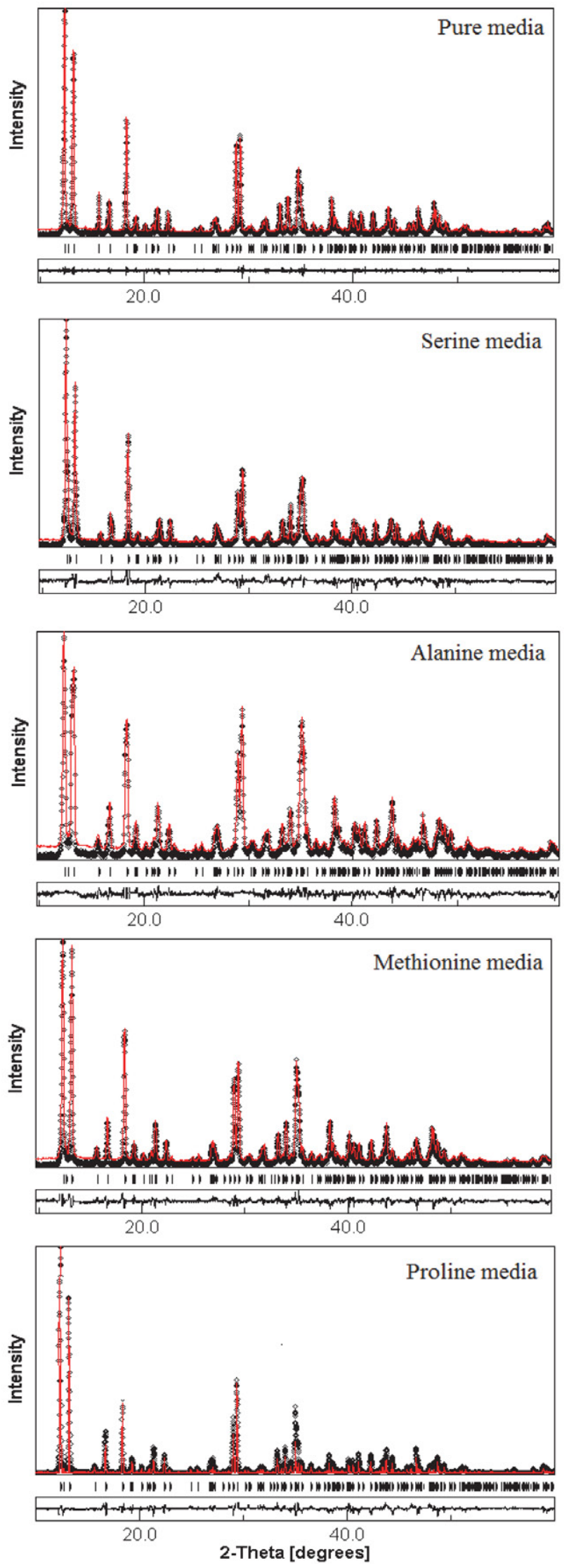

Figure 2. XRD patterns of the CTT crystals obtained in pure media and media supplemented with various amino acids. to the crystallization media did not lead to any change in the crystal structure. Figure 2 shows that the diffraction peaks were slightly shifted to the right and the intensity of these peaks also changed with the addition of amino acids. This could be due to the adsorption of the additives on the crystal faces, which could lead to the formation of imperfections and internal strain in the resulting crystals. The unit cell dimensions for crystals prepared in media supplemented with serine, alanine, methionine, and proline were calculated and the results are shown in Table 1.

Table 1. The unit cell dimensions for crystals obtained in pure media and media supplemented with various amino acids.

\begin{tabular}{lccc}
\hline Media & \multicolumn{3}{c}{ Cell Units } \\
& $\boldsymbol{a}(\AA)$ & $\boldsymbol{b}(\AA)$ & $\boldsymbol{c}(\AA)$ \\
\hline Pure & 9.637 & 10.583 & 9.216 \\
Serine & 9.638 & 10.581 & 9.226 \\
Alanine & 9.647 & 10.593 & 9.233 \\
Methionine & 9.645 & 10.594 & 9.233 \\
Proline & 9.645 & 10.585 & 9.230 \\
\hline
\end{tabular}

\section{2. FTIR Analysis}

FTIR analysis was performed to identify and quantify certain functional groups on the surface of the CTT crystals. Figure 3 shows the FTIR spectra of CTT crystals obtained without and with the different amino acid additives. The FTIR spectrum for the crystals prepared in pure media was in accordance with the literature. ${ }^{15} \mathrm{O}-\mathrm{H}, \mathrm{C}=\mathrm{O}$, $\mathrm{C}-\mathrm{O}$, and metal-oxygen bonds were the main functional groups in the CTT crystals. The three peaks positioned at 3556,3414 , and $3257 \mathrm{~cm}^{-1}$ were assigned to the $\mathrm{O}-\mathrm{H}$ stretching vibrations. The peak at $2986 \mathrm{~cm}^{-1}$ belongs to the $\mathrm{C}-\mathrm{H}$ stretching vibration. The peaks observed at 1575 and $1381 \mathrm{~cm}^{-1}$ were attributed to the $\mathrm{C}=\mathrm{O}$ stretching vibration and $\lambda(\mathrm{C}=\mathrm{O})+\delta(\mathrm{O}-\mathrm{C}=\mathrm{O})$ vibrations, respectively. The peak located at $1281 \mathrm{~cm}^{-1}$ indicated the $\mathrm{O}-\mathrm{H}$ plane bending vibration and the peak at $1146 \mathrm{~cm}^{-1}$ was ascribed to the $\delta(\mathrm{C}-\mathrm{H})+\pi(\mathrm{C}-\mathrm{H})$. In addition, the two peaks at $1061 \mathrm{~cm}^{-1}$ and $1012 \mathrm{~cm}^{-1}$ were assigned to the $\mathrm{O}-\mathrm{H}$ deformation and C-O stretching vibrations, respectively. Finally, the peaks located at 964 and $707 \mathrm{~cm}^{-1}$ were assigned to $\mathrm{Ca}-\mathrm{O}$ bending vibrations. In agreement with the XRD results, FTIR analysis showed that the crystals were in the CTT form.

In order to determine whether the addition of amino acids to the crystallization media affects the functional groups of the CTT and also to analyze the adsorption of these amino acids on the surface of the CTT crystals, FTIR analysis was also performed for the crystals obtained in the presence of amino acids. The FTIR spectra of the crystals prepared in media supplemented with amino acids closely matched the spectra for the crystals prepared in pure media, with all the characteristic peaks of CTT crystals present. 


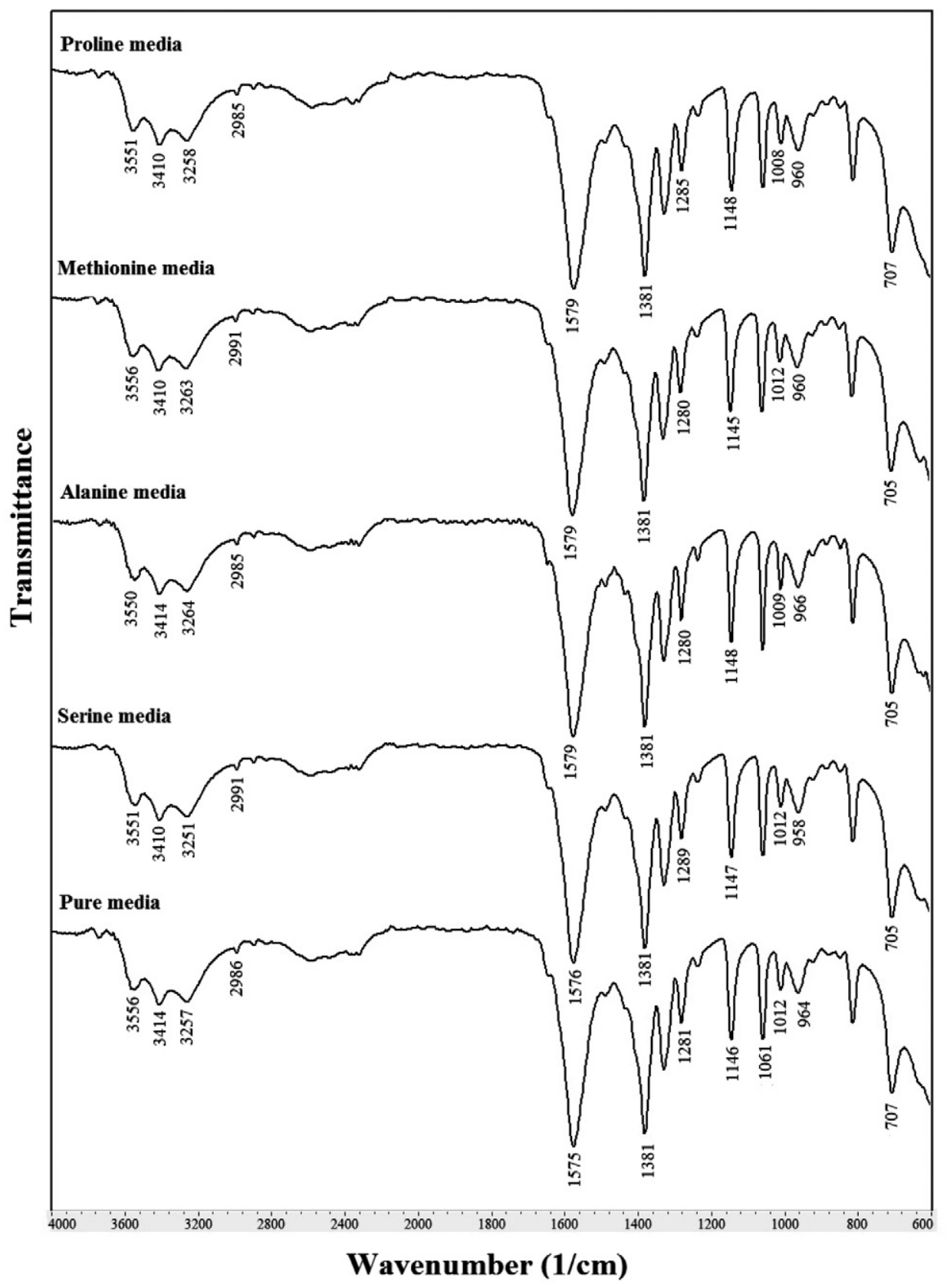

Figure 3. FTIR spectra of the CTT crystals obtained in pure media and media supplemented with various amino acids.

We did not detect any additional peaks relating to the amino acids, which could be because the small amounts of amino acids adsorbed on the surface of the crystals were below the instrument's limit of detection. This may be also attributed to the amino acids being physically adsorbed on the surface of the CTT crystals at the studied concentrations through weak Van der Waals forces.

\section{3. Morphology Analysis}

The effects of the different amino acids on the crystal morphology of CTT are shown in Figure 4 and the corre- sponding length, width, and aspect ratio are shown in Figure 5.

As shown in Figure 4a, the crystals acquired in pure media consisted of prismatic shaped crystals with a smooth surface. There was a high tendency for twin and triplet crystal formation. These crystals had a tendency to break under hydrodynamic conditions and then to form twins and triplets again. The tips of the crystals lost their sharp corners as a result of collisions with each other, the crystallizer wall, and the stirrer. As shown in Figure 5, the aspect ratio of the CTT crystals acquired using pure media was calculated to be 0.255 by dividing the width of the crystal by its length. 

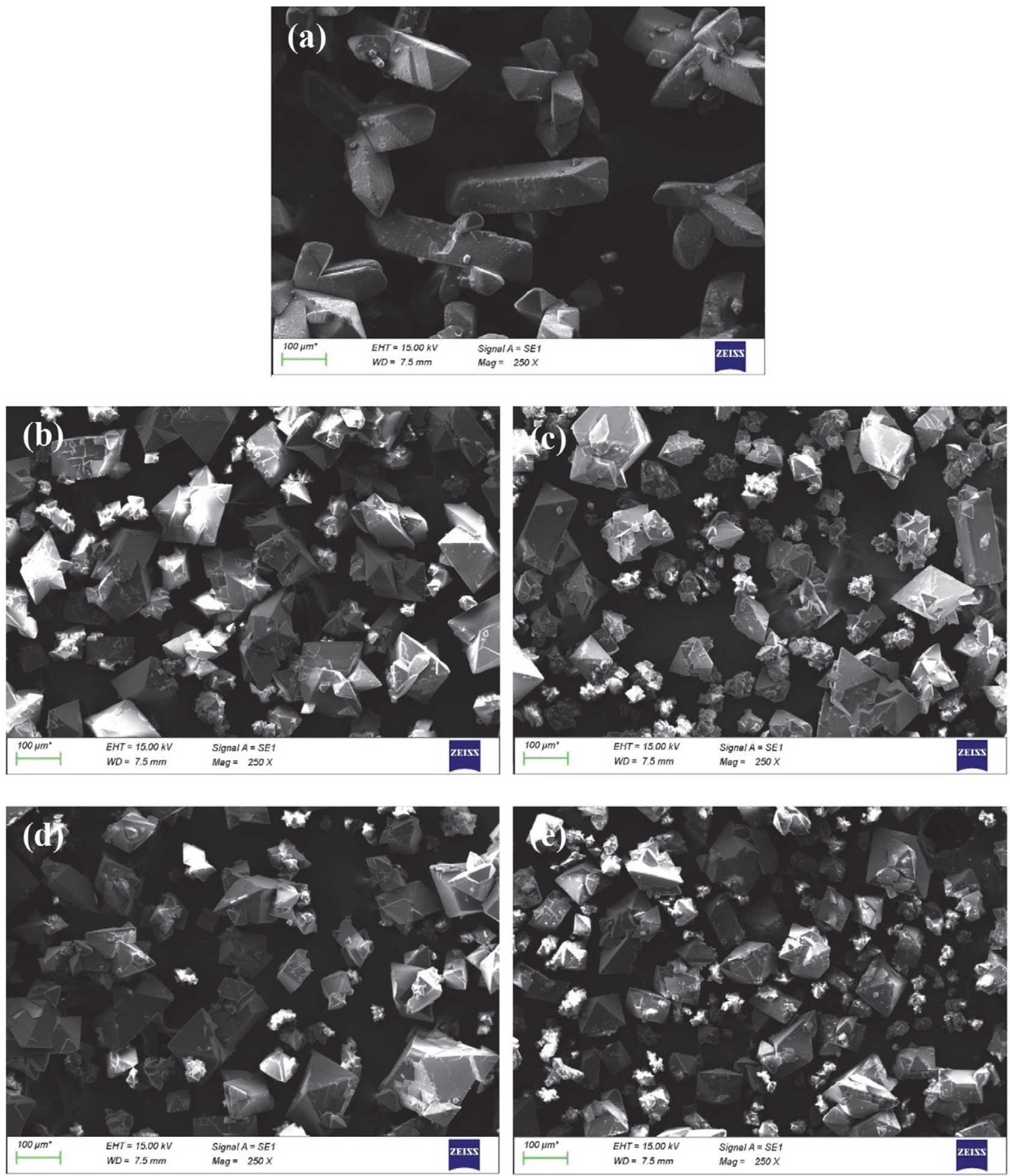

Figure 4. SEM images of the CTT crystals obtained in pure media (a) and in the presence of $200 \mathrm{ppm}$ serine (b), alanine (c), methionine (d), and proline (e).

The morphology of the CTT crystals was significantly affected by the amino acids used. Figures $4 \mathrm{~b}-\mathrm{d}$ clearly show the morphological transformation of CTT crystals from long prismatic to short pyramidal and the surface morphology changed from smooth to rough, indicating that the addition of amino acids affected the crystal structure and led to the formation of defective crystals. The amino acids used as the additive molecules may have greater affinity with certain faces of a particular surfaces. They preferentially interact with kinks on the crystal nu- 


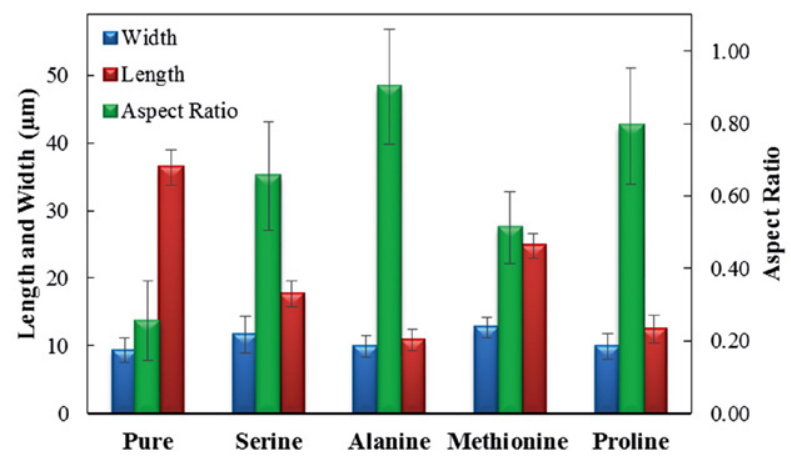

Figure 5. The width, length, and aspect ratio of CTT crystals obtained in pure media and in the presence of $200 \mathrm{ppm}$ serine, alanine, methionine, and proline.

cleus surface and adsorb onto the sites of active growth. These additives interact with $\mathrm{Ca}^{2+}$ ions of the crystal surface with their side terminal carboxyl groups or through hydrogen bonding. This interaction influences the crystallization rate and change the morphology of CTT crystals.

In the presence of serine at a concentration of 200 ppm, the CTT crystals were shortened in length and enlarged in width, resulting in an increased aspect ratio of 0.655. In addition, rhomboid crystals were formed, compared to the prismatic crystals obtained in pure media. The formed rhomboid crystals tended to grow on top of each other and they had a different appearance. Although the surfaces of the crystals were generally smooth, the one surface in particular was affected differently from the other surfaces. Serine can selectively adsorb on the surface of CTT crystals and inhibit the crystal growth. When the SEM image for the crystals prepared with alanine added to the media was examined, it could be clearly seen that this additive had a greater effect than serine. The crystals acquired in the presence of $200 \mathrm{ppm}$ alanine were defective as well as being much smaller and more agglomerated than those obtained in pure media, with an aspect ratio of 0.901 .

As shown in Figure $4 \mathrm{~d}$, the presence of methionine in the crystallization media resulted in the formation of a larger amount of irregular, rhomboid-shaped CTT crystals of non-uniform size with a smooth surface. The aspect ratio of the crystals was 0.512 . When proline was used as the additive, nearly all of the crystals converted from prismatic form to short pyramidal form and some of the crystals were fractured. There were less deformations on the crystal surface than with the other amino acid additives used. In the presence of proline, there was a tendency for surface nucleation. Compared to the other additives, the tendency for surface nucleation was highest in the presence of proline. When the concentration of proline was $200 \mathrm{ppm}$, the aspect ratio was 0.793 .

Accordingly, it can be concluded that the addition of the amino acids serine, alanine, methionine, and proline as effective crystal modifiers results in CTT crystals with different crystal size and morphology. The most effective additive for varying the crystal shape was alanine.

\section{4. Zeta Potential Analysis}

To further reveal the adsorption characteristics of amino acids on CTT crystals zeta potential measurements were performed. The zeta potential analysis results for the crystals prepared with the addition of various amino acids at concentrations from 0 to $200 \mathrm{ppm}$ are presented in Figure 6. The CTT crystals obtained in pure media exhibited a zeta potential of $-21 \pm 1.5 \mathrm{mV}$. The results showed that the addition of amino acids significantly changed the electrical surface charge of the crystals and their zeta potentials were less negative compared to the crystals obtained in pure media.

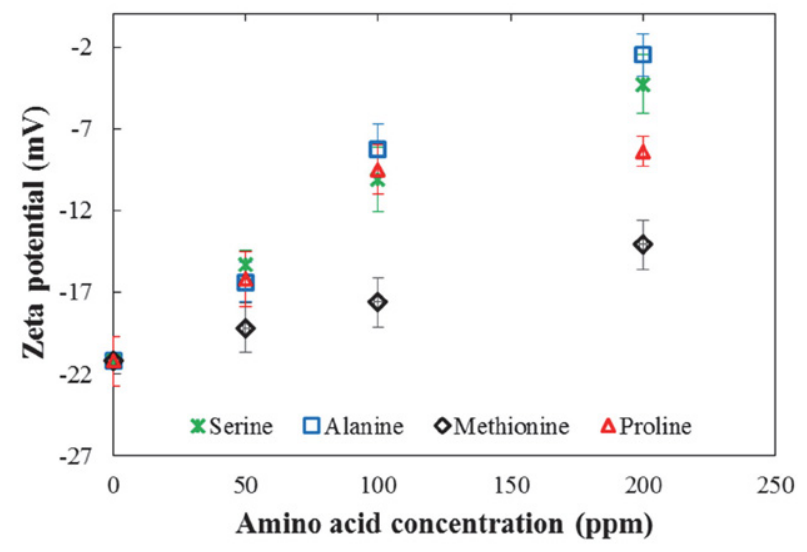

Figure 6. Variation of zeta potential with amino acid concentration.

When the concentration of serine was $50 \mathrm{ppm}$, the zeta potential value was $-15.3 \pm 0.9 \mathrm{mV}$, reaching $-4.3 \pm$ $1.8 \mathrm{mV}$ at a serine concentration of $200 \mathrm{ppm}$. The zeta potentials of the CTT crystals obtained in $200 \mathrm{ppm}$ alanine, methionine, and proline media were $-2.5 \pm 1.3 \mathrm{mV}$, $-14.1 \pm 1.2 \mathrm{mV}$, and $-8.4 \pm 0.8 \mathrm{mV}$, respectively. The zeta potential results show that alanine has the greatest effect on the surface charge of the CTT crystals and that amino acids are adsorbed onto the crystal surface. Moreover, the zeta potentials for the crystals prepared in media supplemented with amino acids increased with the agglomeration tendency of the crystals, in accordance with the SEM results.

\section{5. Thermal Analysis}

We applied thermogravimetric analysis to study the structural evolution and thermal decomposition of the CTT crystals. The thermogravimetric (TG) and differential thermogravimetric (DTG) analysis curves for the crystals obtained in the absence and the presence of the various amino acids at a heating rate of $10{ }^{\circ} \mathrm{C} / \mathrm{min}$ are shown in Figure 7. In accordance with the literature, ${ }^{1,5}$ the thermal decomposition of CTT crystals obtained in pure media proceeded through four different main stages, which can be expressed as follows: 
$\mathrm{CaC}_{4} \mathrm{H}_{4} \mathrm{O}_{6} 4 \mathrm{H}_{2} \mathrm{O} \longrightarrow \mathrm{CaC}_{4} \mathrm{H}_{4} \mathrm{O}_{6}+4 \mathrm{H}_{2} \mathrm{O}$

$\mathrm{CaC}_{4} \mathrm{H}_{4} \mathrm{O}_{6} \longrightarrow \mathrm{CaC}_{2} \mathrm{O}_{4}+2 \mathrm{C}+2 \mathrm{H}_{2} \mathrm{O}$

$\mathrm{CaC}_{2} \mathrm{O}_{4} \longrightarrow \mathrm{CaCO}_{3}+\mathrm{CO}$

$\mathrm{CaCO}_{3} \longrightarrow \mathrm{CaO}+\mathrm{CO}_{2}$
The first decomposition stage included two different peaks at 137 and $191^{\circ} \mathrm{C}$, corresponding to the main weight loss, which were attributed to the loss of four molecules of water of crystallization and the formation of calcium tartrate anhydride $\left(\mathrm{CaC}_{4} \mathrm{H}_{4} \mathrm{O}_{6}\right)$, respectively. In the second $\left(260-356^{\circ} \mathrm{C}\right)$ and third $\left(400-451^{\circ} \mathrm{C}\right)$ decomposition stages, the crystals decomposed into calcium oxalate $\left(\mathrm{CaC}_{2} \mathrm{O}_{4}\right)$ and were further converted into calcium carbonate

a)

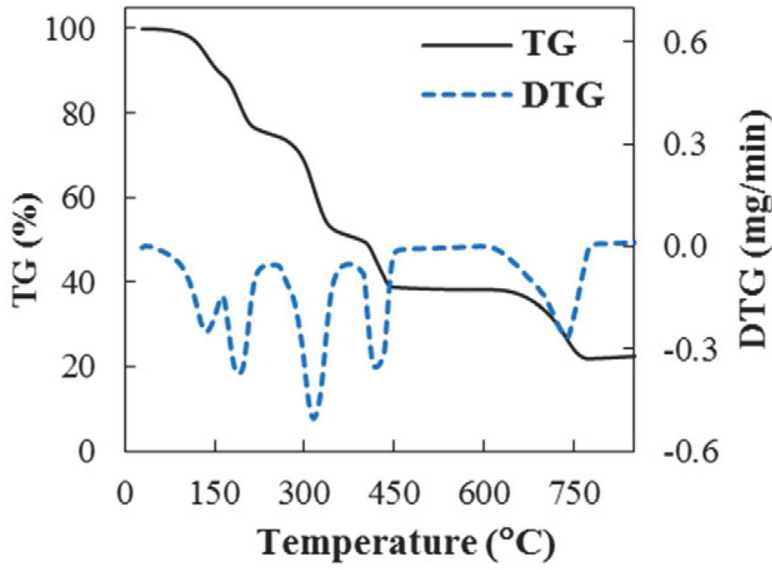

b)

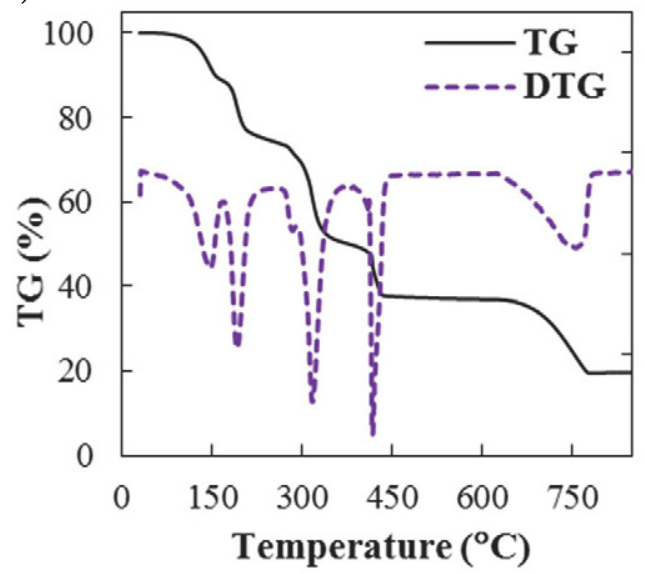

d)

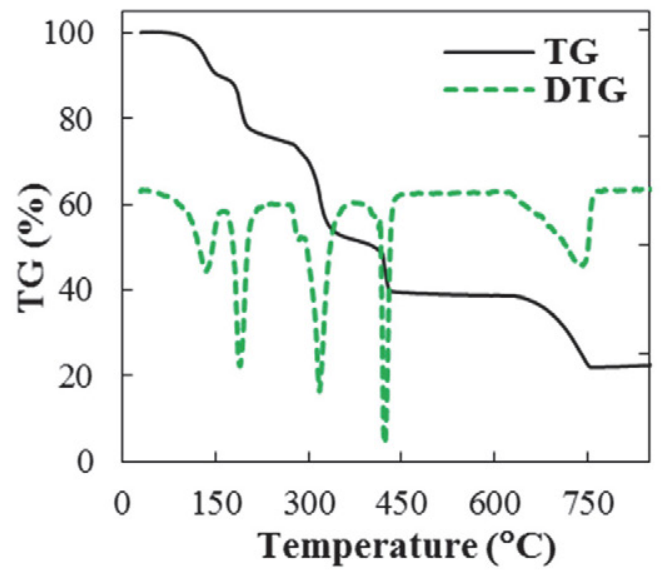

c)

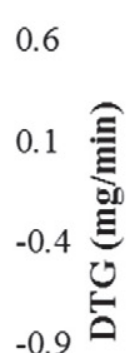

$-1.4$
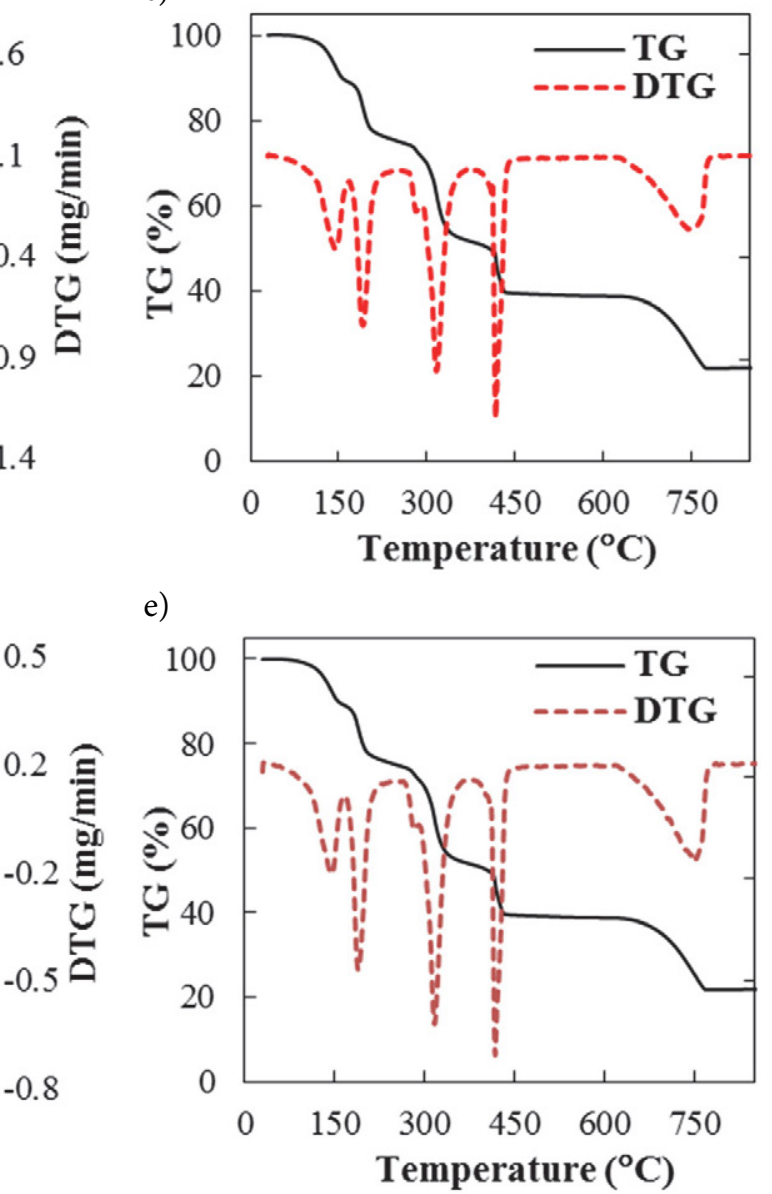

e)

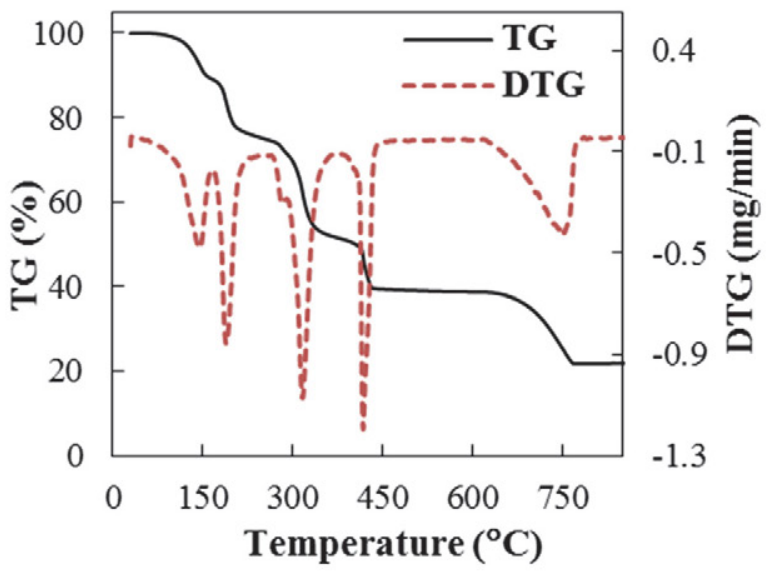

Figure 7. TG/DTG curves of the CTT crystals obtained in pure media (a) and media supplemented with serine (b), alanine (c), methionine (d), and proline (e). 
$\left(\mathrm{CaCO}_{3}\right)$ and carbon monoxide $(\mathrm{CO})$ gas, respectively. The final stage was attributed to the transformation of calcium carbonate $\left(\mathrm{CaCO}_{3}\right)$ to calcium oxide $(\mathrm{CaO})$ and carbon dioxide $\left(\mathrm{CO}_{2}\right)$ gas in the temperature range of 623$776{ }^{\circ} \mathrm{C}$. Above this temperature, the weight loss remained stable until the end of the decomposition process. The TG/ DTG results showed that the obtained crystals were in tetrahydrate form.

As can be seen in Figure 7, similar to the crystals obtained in pure media, the four main decomposition stages were detected for all the amino acids used. Unlike the crystals from the pure media, a low-intensity shoulder was detected at $\sim 297^{\circ} \mathrm{C}$ owing to the decomposition of the amino acid additives. This may be attributed to the loss of amino group from the amino acid molecules. The weight loss from the CTT crystals obtained in pure media was $77.9 \%$, which was in agreement with the literature. ${ }^{16}$ Increments of $1.5 \%, 0.8 \%, 0.3 \%$, and $0.6 \%$ were observed for CTT crystals obtained in serine, alanine, methionine, and proline, respectively. The increased weight loss indicated that the amino acids had been adsorbed onto and interacted with the surface of the CTT crystals. The amino acids used had a significant effect on the temperatures of the decomposition peaks during the thermal decomposition of CTT. The peaks shifted towards the higher temperature region in the presence of the additives.

\section{6. Kinetic Analysis}

The FWO, KAS and Starink methods were applied to determine the activation energy of CTT was calculated in the four decomposition zones. Table 2 shows the specific decomposition temperatures, namely initial temperature, $\mathrm{T}_{\mathrm{i}}$, maximum peak temperature, $\mathrm{T}_{\max }$, and final temperature, $\mathrm{T}_{\mathrm{f}}$, for the CTT crystals obtained in pure media.

Table 2. Specific temperatures of the CTT crystals decomposition process.

\begin{tabular}{lcccc}
\hline Media & $\begin{array}{c}\text { Heating Rate } \\
\left({ }^{\circ} \mathbf{C} / \mathbf{m i n}\right)\end{array}$ & $\begin{array}{c}\mathbf{T}_{\mathbf{i}} \\
\left({ }^{\circ} \mathbf{C}\right)\end{array}$ & $\begin{array}{c}\mathbf{T}_{\max } \\
\left({ }^{\circ} \mathbf{C}\right)\end{array}$ & $\begin{array}{c}\mathbf{T}_{\mathbf{f}} \\
\left({ }^{\circ} \mathbf{C}\right)\end{array}$ \\
\hline Stage I & 5 & 82 & 183 & 202 \\
& 10 & 88 & 191 & 222 \\
Stage II & 20 & 124 & 198 & 235 \\
& 5 & 255 & 306 & 328 \\
& 10 & 260 & 315 & 356 \\
Stage III & 20 & 278 & 324 & 366 \\
& 5 & 390 & 412 & 429 \\
\multirow{4}{*}{ Stage IV } & 10 & 400 & 419 & 451 \\
& 20 & 409 & 427 & 470 \\
& 10 & 611 & 722 & 757 \\
& 20 & 623 & 737 & 774 \\
& 5 & 659 & 773 & 814 \\
\hline
\end{tabular}

Table 2 clearly shows that as the heating rate was increased, the characteristic temperatures for each decom- position stage were shifted to higher values, which was attributed to the effect of the different heat-transfer rates on the thermal decomposition kinetics.

Figure 8 presents the plots of the three models of the CTT for conversion degrees from 0.1 to 0.9 at different heating rates for the first decomposition stage. The experimental results show high correlation with the three models, with $\mathrm{R}^{2}$ values of $0.9324-0.9999$, which suggests that the results are highly reliable (Figure 8). The parallel lines indicate that there is similar kinetic behavior in the range of $0.10-0.40$, which suggests that all of the tested models follow the same reaction mechanism for CTT decomposition. However, the reaction mechanism is not similar for all conversion values, particularly at higher conversions, which suggests that there may be a complex multi-step mechanism involving parallel, competitive, and consecutive reactions with different energies.
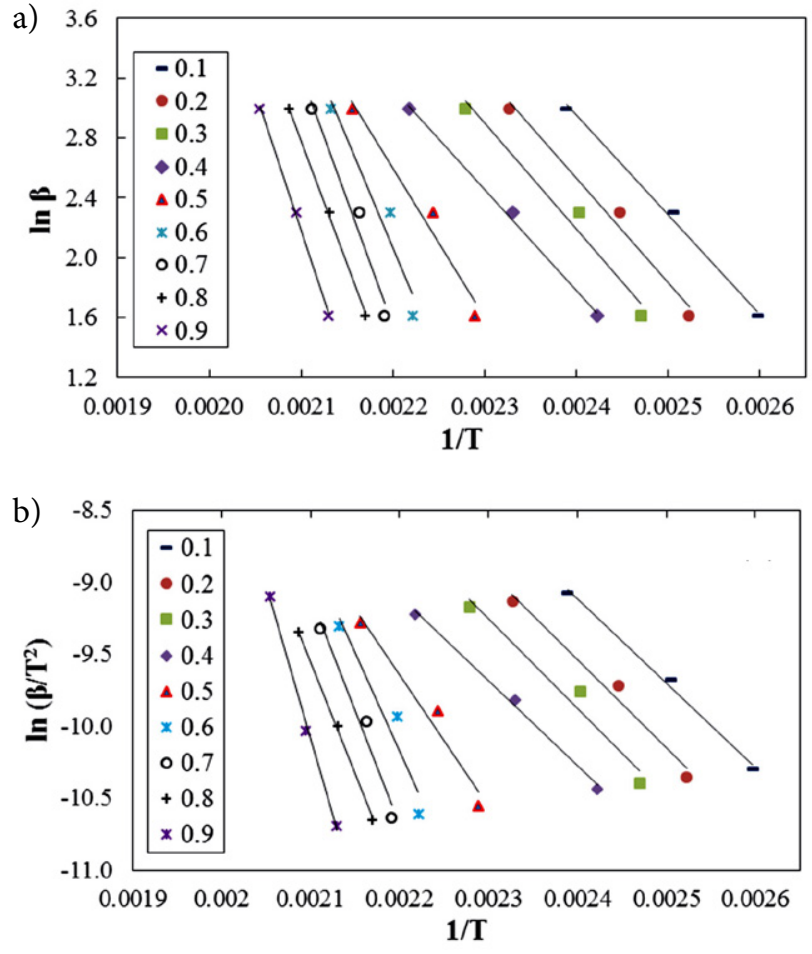

c)

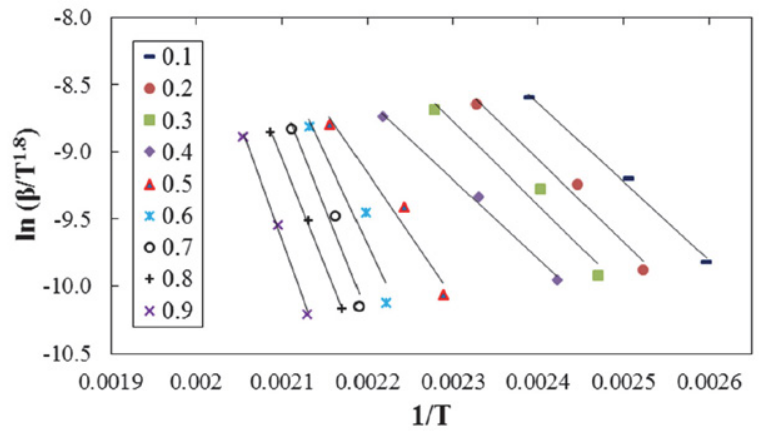

Figure 8. Plots of (a) FWO, (b) KAS, and (c) Starink methods for the first decomposition stage of the CTT crystals obtained in pure media. 
The activation energy (i.e., the minimum amount of energy required to initiate a reaction) is plotted as a function of the degree of CTT conversion for four different stages in Figure 9.
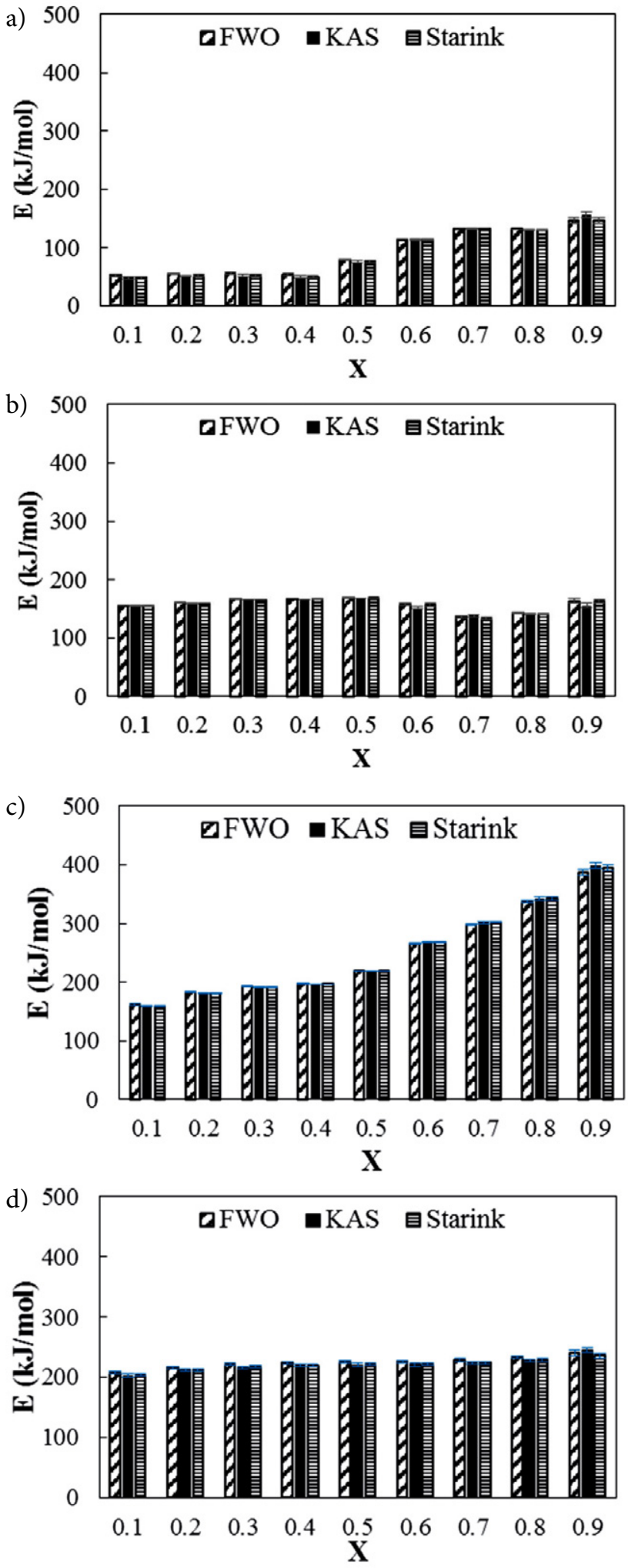

Figure 9. Activation energy versus conversion degree for the CTT crystals for a) Stage I b) Stage II c) Stage III d) Stage IV.
The results show that the minimum mean activation energy values from the FWO, KAS, and Starink methods for the first decomposition stage were 91.0, 89.6, and 88.6 $\mathrm{kJ} / \mathrm{mol}$, respectively, which are similar to the activation energy reported in the literature for the dehydration of CTT crystals. ${ }^{16,17}$ There is good agreement among the calculated values with little deviation, demonstrating the consistency and reliability of the activation energies calculated using the three different kinetic models and various heating rates. The minor differences in the activation energy values arose from the approximations, assumptions, and mathematical formulations used in the different models. The mean activation energies for the second, third and fourth decomposition stages were calculated to be 158.0, 155.9 , and $156.8 \mathrm{~kJ} / \mathrm{mol} ; 249.1,250.7$, and $250.5 \mathrm{~kJ} / \mathrm{mol}$; 224.8, 221.1, and $220.4 \mathrm{~kJ} / \mathrm{mol}$, respectively, using the FWO, KAS, and Starink models. According to the calculated activation energy values, less energy was needed for the first decomposition stage but the third decomposition stage related to the decomposition of carbon monoxide required a higher amount of energy to proceed.

\section{Conclusions}

Different concentrations of various amino acids were used to regulate the crystal size and morphology of CTT crystals, which were characterized in detail. Moreover, the thermal decomposition kinetics of the crystals obtained in pure media were examined. The general conclusions obtained can be summarized as follows:

- The XRD results showed that CTT was the only detectable crystalline phase for the crystals obtained in the absence and the presence of the amino acids.

- SEM analysis results indicated that the amino acids used have the ability to change the morphology of CTT crystals. The SEM images showed that the crystal surface varied from smooth to rough, which suggested that the amino acids used affected the crystal morphology, causing the formation of defective and irregular crystals.

- The morphology analysis results revealed that the CTT crystals obtained in the presence of all of the tested amino acids were shortened in length and enlarged in width, resulting in an increased aspect ratio.

- With increasing amino acid concentration, the surface charge of the crystals became more positive. For instance, the zeta potential value changed from $-21.2 \pm$ $1.5 \mathrm{mV}$ for crystals prepared in pure media to $-2.5 \pm 1.3$ $\mathrm{mV}$ for the crystals prepared in media supplemented with 200 ppm alanine.

- Thermal decomposition kinetics for pure media were examined using different iso-conversional methods. Increasing the conversion from 0.1 to 0.9 changed the calculated activation energy values, which led to the different decomposition characteristics of the CTT crystals. 
Using the different kinetic methods, the average activation energies for the first, second, third, and fourth stages were calculated to be $89.7,156.9,250.1$, and 222.1 $\mathrm{kJ} / \mathrm{mol}$, respectively.

\section{Acknowledgements}

This work was supported by Marmara University Scientific Research Projects Commission under the funding FEN-C-YLP-230119-0009.

\section{References}

1. X. Sahaya Shajan, C. Mahadevan, Cryst. Res. Technol. 2005, 40(6), 598-602. DOI:10.1002/crat.200410389

2. S. S. Sonawane, S. J. Nandre, R. R. Ahire, S. J. Shitole, Der Pharma Chem. 2014, 6(3), 33-38.

3. M. Tailor, V. Joshi, Adv. Appl. Sci. Res. 2014, 5(6), 115-119.

4. C. Kleinguetl, J. C. Williams Jr, J. C. Lieske, M. Daudon, M. E. Rivera, P. J. Jannetto, J. Bornhorst, D. Rokke, E. T. Bird, J. E. Lingeman, M. M. El Tayeb, Urology. 2019, 126, 49-53.

DOI:10.1016/j.urology.2019.01.005

5. X. Sahaya Shajan, C. Mahdevan, Bull. Mater. Sci. 2004, 27(4), 327-331. DOI:10.1007/BF02704767

6. M. E. Torres, T. López, J. Stockel, X. Solans, M. García-Vallés,
E. Rodríguez-Castellón, C. González-Silgo, J. Solid State Chem. 2002, 163, 491-497. DOI:10.1006/jssc.2001.9435

7. K. Suryanarayana, S.M. Dharmaprakash, Mater. Lett. 2000, 42, 92-96. DOI:10.1016/S0167-577X(99)00165-2

8. E.V. Shlyakhova, N. F. Yudanov, Y. V. Shubin, L. I. Yudanova, L. G. Bulusheva, A. V. Okotrub, Carbon. 2009, 47(7), 17011707. DOI:10.1016/j.carbon.2009.02.018

9. C. Gonzalez-Silgo, M. E. Torres, T. Lopez, J. Gonzalez-Platas, A. C. Yanes, J. D. Castillo, J. F. Peraza, X. Solan, Mater. Lett. 2006, 60(12), 1509-1514. DOI:10.1016/j.matlet.2005.11.068

10. T. Ozawa, Bulletin Chem. Soc. Japan. 1965, 38, 1881-1886. DOI:10.1246/bcsj.38.1881

11. J. H. Flynn, L. A. Wall, J. Res. Nat. Bur. Stand. 1966, 70, 487523. DOI:10.6028/jres.070A.043

12. T. Akahira, T. Sunose, Res. Rep. Chiba Inst. Technol (Sci Technol). 1971, 16, 22-31.

13. M. Starink, Thermochim. Acta. 1966, 288, 97-104. DOI:10.1016/S0040-6031(96)03053-5

14. P. P. Pradyumnan, C. Shini, Indian J. Pure Ap. Phy. 2009, 47, 199-205.

15. B. B. Parekh, V. S. Joshi, V. Pawar, V. S. Thaker, M. J. Joshi, Cryst. Res. Technol. 2009, 44(1), 31-35.

DOI:10.1002/crat.200800405

16. V. S. Joshi, Int. J. Innov. Res. Sci. Eng. Technol. 2016, 5(5), 8191-8197.

17. V. S. Joshi, M. Joshi, Indian J. Phys. 2001, 75A(2), 159-163.

\section{Povzetek}

S to raziskavo smo preučili vpliv nekaterih aminokislin, konkretno serina, alanina, metionina in prolina na kristale kalcijevega tartrata tetrahidrata (CTT). Kristalizacijo smo izvajali šaržno, pri temperaturi $25^{\circ} \mathrm{C}, \mathrm{pH}$ vrednosti 9 , dodali pa aminokisline v treh različnih koncentracijah. Kristale CTT smo okarakterizirali z XRD, FTIR, SEM, njihovo velikostjo in zeta potencialom. Za vse uporabljene aminokisline se je izkazalo, da znatno vplivajo na površinski naboj, velikost in morfologijo kristalov. Kristale dobljene brez dodanih aminokislin smo termično razkrojili, pri čemer smo spremljali kinetiko razkroja. Kinetiko smo preučili z uporabo treh različnih kinetičnih modelov, Flynn-Wall-Ozawa (FWO), Kissinger-Akahira-Sunose (KAS) in Starink. Povprečne aktivacijske energije kristalov za prvo, drugo, tretjo in četrto stopnjo razklopa so bile za FWO model 91.0, 158.0, 249.1, in 224.8 kJ/mol, za KAS model 89.6, 155.9, 250.7 in $221.1 \mathrm{~kJ} /$ mol ter za Starink model 88.6, 156.8, 250.5 in 220.4 kJ/mol. Rezultati študije nam omogočijo, da lahko izberemo aminokislin, s katero dobimo željeno morfologijo CTT kristalov, preučena pa je tudi kinetika razklopa.

Except when otherwise noted, articles in this journal are published under the terms and conditions of the Creative Commons Attribution 4.0 International License 